\title{
Assessment of genetic diversity among Egyptian garlic landraces based on morphological characteristics and ISSR markers
}

\author{
Gehan A. Elsharkawy ${ }^{1}$, H.H. Hegazi ${ }^{1}$, E. Azab ${ }^{2,3}$, A.A. Gobouri ${ }^{4}$ and S.A. Sayed ${ }^{5}$ \\ ${ }^{1}$ Vegetable Crops Department, Faculty of Agriculture, Alexandria University, Alexandria, Egypt \\ 2 Department of Biotechnology, College of Science, Taif University, Taif, Saudi Arabia \\ ${ }^{3}$ Botany and Microbiology Department, Faculty of Science, Zagazig University, Zagazig, Sharkia, Egypt \\ ${ }^{4}$ Department of Chemistry, College of Science, Taif University, Taif, Saudi Arabia \\ ${ }^{5}$ City of Scientific Research and Technological Applications (SRTA-City), New Borg El-Arab, Alexandria, Egypt
}

\section{Summary}

Genetic diversity among twenty-seven Egyptian garlic (Allium sativum L.) cultivars and ecotypes were studied based on morphological characteristics and ISSR molecular markers. Euclidean distances and Ward's method for cluster analysis were performed among studied genotypes using 14 morphological characters. The correlation coefficients for the pairs of the thirteen studied characters with total yield revealed highly significant positive correlation $(P \leq 0.001)$ between total yield and certain parameters, over the two growing seasons. These parameters were: leaf width $(0.62)$, plant fresh weight $(0.99)$, foliage fresh weight $(0.74)$, and bulb's characteristics including its length $(0.62)$, diameter $(0.66)$ and fresh weight (0.79). For pair-wise comparison, Euclidean distances among studied genotypes ranged from 1.04 to 11.00 . No $100 \%$ similarity within pair could be found (distances $=0.00$ ). Moreover, obtained dendrogram from cluster analysis displayed two main clusters which include 27 garlic genotypes; each cluster contains two groups. Meanwhile, clustering of the studied cultivars and ecotypes did not correspond to the geographical origin. It was clearly distinguished between cultivars and ecotypes which have purple and white bulbs. However, conducted ISSR markers using four primers (UBC-812, UBC-817, UBC-825 and UBC-842 primers) produced 55 amplified fragments, 54 of them were polymorphic with $98.18 \%$ polymorphism. Jaccard's coefficients revealed that Balady, Balady-Al Wadi, Clone-1 and Clone-24 were genetically similar. Also, Clone-21 and Salaqus presented $100 \%$ genetic similarity. Jaccard's coefficients of the other studied genotypes ranged from 0.08 to 0.96 , suggesting a broad genetic base of Egyptian garlic genotypes. Based on ISSR markers, it was found that two main clusters for the studied genotypes varied from that of morphological characters bases. The first one included twenty-six genotypes, which were grouped into three groups, while the second cluster contained only Clone-5 with similarity coefficient ranging from 0.08 to 0.18 .

Keywords

Allium sativum L., genetic diversity, morphological characters, ISSR markers

\section{Significance of this study}

What is already known on this subject?

- Garlic genotypes show morphological, physiological and genetic variations, which is reflected in its interaction with the environment and its yield performance. Studying these variations in the available genotypes that are adapted to the environment provides information for plant breeding.

What are the new findings?

- Vegetative, yield and molecular assay of 27 Egyptian garlic cultivars and ecotypes were evaluated, and its genetic background has been clarified. Therefore, a breeding program can be established based on this.

What is the expected impact on horticulture?

- In the short term, it can help garlic producers to improve their quality and quantity yield at the study area and similar conditions. While in the long term, it is helpful in breeding program, knowing the existing and widespread garlic germplasm and finally knowing the genotypes by their proper names and origins.

\section{Introduction}

Vavilov (1926) suggested Central Asia as a primary center of garlic. However, the Mediterranean region was reported as the secondary center of garlic diversity (Vavilov, 1951). Heredia-García (2000) classified commercial types of garlic based on bulb color and temperature requirements into: (1) violet or Asian (cultivated in subtropical regions), and (2) pink (needs long photoperiods and has low requirements for low temperature), (3) white (needs long photoperiods, and has medium to high requirements for temperature), and (4) purple (needs long photoperiods and periods of low temperature). Garlic can also be classified into hard-neck and soft-neck garlic. Hard-neck garlic forms a floral scape whose flowers normally abort and whose end produces topsets, while soft-neck garlic does not form a scape. The majority of garlic cultivated for commercial purposes is soft-neck type because it is easier to cultivate and it has a longer shelf life (Kamenetsky, 2007).

Garlic is grown all over the world at different temperate and subtropical climates (Fritsch and Friesen, 2002). It was reported (2010) that the main producer of garlic is China 
with 136 million tons (77.4\% of the total world production) obtained from an area of 664,300 ha (hectare $=2.38$ feddan) with an average of 20.59 ton ha $^{-1}$. On the other hand, Egypt is the fourth producing country of the world's output. According to a 2010 report, the cultivated area of garlic in Egypt reached 9,674 ha yielding 244,626 tons with an average of 25.29 ton ha-1. This production is considered higher compared to garlic growing in other countries of the world (FAO, 2012).

Garlic is a species of vegetative propagation, showing high morphological diversity between cultivars. Besides, its clones, they have specific adaptations to different agroclimatic regions (Figliuolo et al., 2001). A wide range of morphological variations has been observed in garlic, including flowering ability, flower traits, leaf traits, bulb traits, bulbing response to environment and plant maturity (Senula and Keller, 2000). Genotype response to environmental variations is an important factor to be studied and provides information to breeder and producer.

Molecular markers have been used to estimate garlic plants genetic diversity. DNA-based markers are less affected by age, physiological condition of samples and environmental factors. They are not tissue-specific and can be detected at any phase of plant development (Abdel-halim, 2014). Therefore, molecular characterization of garlic germplasms has been performed around the world with different molecular markers such as RAPD marker (Bekheet, 2006; Paredes et al., 2008), AFLP marker (Volk et al., 2004; Phillips et al., 2008), SSR marker (Zhao et al., 2011; Jo et al., 2012) and ISSR marker (Jabbes et al., 2011; Chen et al., 2014; El-Nagar and El-Zohiri, 2015).

ISSRs have been successfully used to estimate the extents of genetic diversity at both inter- and intra-specific levels in a wide range of crops include garlic (Mukherjee et al., 2013).

The present study consisted of two parts; the first part aimed to study genetic diversity of 27 Egyptian local cultivars and ecotypes of garlic based on morphological characteristics, while the second part aimed to determine the genetic diversity of the 27 local cultivars and ecotypes of Egyptian garlic based on ISSR molecular markers.

\section{Materials and methods}

\section{Genetic diversity assessment based on morphological characteristics}

Twenty-seven Egyptian cultivars and ecotypes of garlic (Table 1) were collected from diverse regions in Egypt (Figure 1) and used as plant material during the course of this study. Two field experiments were carried out at the experimental station in the City of Scientific Research and Technological Applications (SRTA-City), New Borg El-Arab, Egypt (Approximate lat. 30 $53^{\prime} 36^{\prime \prime} \mathrm{N}$, long. 29 $32^{\prime} 48.27^{\prime \prime} \mathrm{E}$ ). These two field experiments aimed to evaluate the morphological, bulb characteristics and total yield of 27 cultivars and ecotypes of garlic during two growing seasons of 2015 and 2016. Each experimental unit consisted of 2 rows, $4 \mathrm{~m}$ long and $50 \mathrm{~cm}$ wide, occupying an area of $4 \mathrm{~m}^{2}$. The experimental layout used randomized complete block design (RCBD) with three replicates. Gloves of the 27 local cultivars and ecotypes of garlic were sown on $8^{\text {th }}$ of September in both growing seasons at $10 \mathrm{~cm}$ distance apart within the row and $50 \mathrm{~cm}$ between the two adjacent rows.

The data were recorded at maximum growth stage and after harvesting (192 days from planting date). Ten randomly selected plants from each experimental unit were chosen
TABLE 1. Genotypes, bulb characteristics and regions of the 27 landraces of Egyptian garlic.

\begin{tabular}{|c|c|c|c|}
\hline Genotype & $\begin{array}{l}\text { Bulb skin } \\
\text { color }\end{array}$ & Clove characteristics & Regions \\
\hline Balady & \multirow{16}{*}{ White } & \multicolumn{2}{|c|}{ Small size, arranged El-Minia governorate } \\
\hline Balady-Al Wadi & & \multirow{15}{*}{$\begin{array}{l}\text { from } 20 \text { to } 45 \text { per } \\
\text { bulb, organized } \\
\text { in more than five } \\
\text { groups }\end{array}$} & $\begin{array}{l}\text { El-Wadi El-Gadid } \\
\text { governorate }\end{array}$ \\
\hline Clone-1 & & & El-Minia governorate \\
\hline Clone-5 & & & El-Minia governorate \\
\hline Clone-18 & & & El-Minia governorate \\
\hline Clone-22-W & & & El-Minia governorate \\
\hline Clone-24 & & & El-Minia governorate \\
\hline Clone-25 & & & El-Minia governorate \\
\hline El Ewinat & & & $\begin{array}{l}\text { El-Wadi El-Gadid } \\
\text { governorate }\end{array}$ \\
\hline Farmer's clone & & & El-Minia governorate \\
\hline Salaqus-3 & & & $\begin{array}{l}\text { Bani Swaife } \\
\text { governorate }\end{array}$ \\
\hline Aswan & & & Aswan governorate \\
\hline Borg El-Arab & & & Alexandria governorate \\
\hline El Behera & & & El Behera governorate \\
\hline El Fayoum-1 & & & El Fayoum governorate \\
\hline El Fayoum-2 & & & El Fayoum governorate \\
\hline Egaseed-1A & \multirow[t]{11}{*}{ Purple } & \multirow{8}{*}{$\begin{array}{l}\text { Medium size, } \\
\text { arranged from } \\
13 \text { to } 20, \text { organized } \\
\text { in } 3 \text { or } 4 \text { groups }\end{array}$} & Egaseed company \\
\hline Egaseed-1B & & & Egaseed company \\
\hline Egaseed-2 & & & Egaseed company \\
\hline Egaseed-3 & & & Egaseed company \\
\hline Salaqus & & & $\begin{array}{l}\text { Bani Swaife } \\
\text { governorate }\end{array}$ \\
\hline Clone-21 & & & El-Minia governorate \\
\hline Clone-22-R & & & El-Minia governorate \\
\hline Al Ayat-1 & & & El-Giza governorate \\
\hline Bany gonamy & & \multirow{3}{*}{$\begin{array}{l}\text { Large size, arranged } \\
\text { from } 8 \text { to } 13 \text {, } \\
\text { organized in } 1 \text { or } 2 \\
\text { groups }\end{array}$} & $\begin{array}{l}\text { Bani Swaife } \\
\text { governorate }\end{array}$ \\
\hline Sids-40-R.S. & & & $\begin{array}{l}\text { Bani Swaife } \\
\text { governorate }\end{array}$ \\
\hline Sids-40-Ayat & & & El-Giza governorate \\
\hline
\end{tabular}

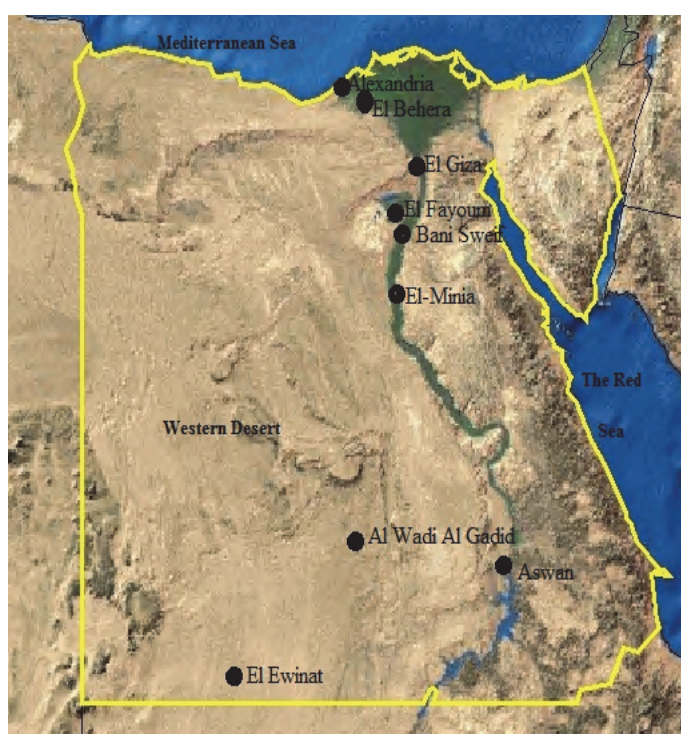

FIGURE 1. Map of collection regions of studied garlic ecotypes from different Egyptian governorates. 
TABLE 2. List of the primers and their nucleotide sequences used in the study for ISSR analysis.

\begin{tabular}{llc}
\hline Name & Sequence (5' to $3^{\prime}$ ) & Annealing temp. \\
\hline UBC-812 & GAGAGAGAGAGAGAGA & 45 \\
UBC-817 & CACACACACACACACAA & \\
UBC-825 & ACACACACACACACT & \\
UBC-842 & CTCTCTCTCTCTCTCTYG & \\
UBC-868 & GAAGAAGAAGAAGAAGAA & \\
\hline
\end{tabular}

for the determination of vegetative growth characteristics [Average plant height $(\mathrm{cm})$; average number of leaves per plant; average leaf length $(\mathrm{cm})$; average leaf width $(\mathrm{mm})$; plant fresh weight $(\mathrm{g})$; foliage fresh weight $(\mathrm{g})$; and foliage dry matter percentage]. Dry matter percentage content for each sample was calculated using the following formula:

Dry matter $=($ dry weight $/$ fresh weight $) \times 100$

Bulb characteristics and total yield [average bulb fresh weight (g); average bulb height ( $\mathrm{mm})$; average bulb diameter ( $\mathrm{mm}$ ); and average bulb dry matter percentage; average number of cloves per bulb; average clove weight (g); and total fresh yield (ton ha-1)] were measured. Data of the two field experiments were used for representing genotypes relationships to the development of cluster among them. One of the objectives of this work is the determination of the genetic diversity of representing groups within the studied genotypes based on morphological characters. Cluster analysis of genotypes was performed using SAS program v. 9.3 (SAS Institute, 2012) and using Ward's method. Euclidean distances between genotypes were calculated using the mean values of the studied characters of the two growing seasons (2015 and 2016). Euclidean distances between genotypes and Ward's method for cluster analysis were performed by SAS program v. 9.3 (SAS Institute, 2012).

\section{Genetic diversity assessment based on ISSR molecular markers}

This experiment was conducted in the Laboratory of Bioprocess Development Department, City for Scientific Research and Technology Applications, New Borg El-Arab City, Alexandria, Egypt. The total DNA was extracted from healthy leaves of the garlic plants grown in the field, using modified cetyl-trimethyl ammonium bromide (CTAB) method according to Doyle and Doyle (1987). The DNA concentration was assessed spectrophotometrically at $260 \mathrm{~nm}$, and quality was assessed by the $260 / 280$ ratio (Sambrook et al., 1989). ISSR analysis was performed on a total of five primers (Table 2). Four primers provided clear and informative amplification profiles and were selected to survey variation among all cultivars and ecotypes. PCR reaction was performed in $25 \mu \mathrm{L}$ (containing $5 \mu \mathrm{L} 5 \times$ PCR buffer, $2 \mu \mathrm{L}$ dNTP, $1 \mu \mathrm{L}$ primer, $0.20 \mu \mathrm{L}(1 \mathrm{U})$ Taq DNA polymerase, $1 \mu \mathrm{L}$ DNA and $15.8 \mu \mathrm{L}$ distilled water). PCR steps were an initial denaturation step of $5 \mathrm{~min}$ at $94^{\circ} \mathrm{C}, 35$ cycles of $1 \mathrm{~min}$ at $94^{\circ} \mathrm{C}$, $45 \mathrm{sec}$. at $45^{\circ} \mathrm{C}, 2 \mathrm{~min}$ at $72^{\circ} \mathrm{C}$, followed by a the final step of $10 \mathrm{~min}$ at $72^{\circ} \mathrm{C}$. PCR reactions were run in an Eppendorf thermal cycler. Amplified products obtained from ISSR analysis were separated on $1 \%$ agarose gel in $0.5 \times$ TBE buffer, stained with ethidium bromide. Images were captured and documented on gel documentation system.

Data of ISSR analysis were scored for computer analysis on the basis of the presence (1) or absence (0) of the ampli- fied products for each primer. Jaccard's coefficients matrices and cluster analysis using unweighted pair-group method with arithmetic means (UPGMA) were performed by PAST 3.15 software (Hammer et al., 2001).

\section{Results}

\section{Phenotypic correlation coefficient}

Data in Table 3 show the values of estimated correlation coefficient for the pairs of thirteen studied characters and total yield. The data revealed highly significant positive correlation $(P \leq 0.001)$ among the total yield (ton ha-1) and leaf width (0.62), plant fresh weight (0.99), foliage fresh weight (0.74), bulb length (0.62), diameter (0.66), and fresh weight $(0.79)$ throughout the two growing seasons.

\section{Genetic diversity assessment based on morphological characteristics}

Fourteen quantitative morphological characters were used for Ward's cluster analysis. They are, plant height, leaves number per plant, leaf length and width, plant fresh weight, foliage fresh weight, bulb fresh weight, height and diameter, cloves no. per bulb, clove weight, foliage and bulb dry matter content and total yield. Euclidean distances among studied genotypes (Table 4) ranged from 1.04 to 11.00 , no pair could be found with $100 \%$ similarity (distances $=0.00$ ), in pair-wise comparison. Generally, Balady and Salaqus-3 showed the minimum value of Euclidean distances (1.04), reflecting highest morphological similarity among them, while the maximum values were given by Borg El-Arab against Farmer's clone, Egaseed-3 and El Ewinat (11.00, 10.26, and 10.16, respectively).

In addition, dendrogram obtained from cluster analysis revealed that 27 garlic genotypes were clustered into two main clusters; the first one covered genotypes which have white bulb, and were clustered into two groups. Group "1-A" includes Balady, Salaqus-3, El Fayoum-2, El Behera, Balady Al-Wadi, Aswan, Clone-5, El Ewinat, Farmer's clone, Clone-22-W, Clone-25, El Fayoum-1, Clone-1, Clone-18 and

TABLE 3. Phenotypic correlation coefficient between total yield (ton ha-1) and studied characters of the 27 garlic local cultivars and ecotypes of 2015/2016 and 2016/2017.

\begin{tabular}{lc}
\hline Character & Correlation coefficient values \\
\hline Plant height $(\mathrm{cm})$ & $0.06 \mathrm{~ns}$ \\
Leaves number plant $^{-1}$ & $0.12 \mathrm{~ns}$ \\
Leaf length $(\mathrm{cm})$ & $0.04 \mathrm{~ns}$ \\
Leaf width $(\mathrm{mm})$ & $0.62^{* * *}$ \\
Plant fresh weight $(\mathrm{g})$ & $0.99^{* * *}$ \\
Foliage fresh weight $(\mathrm{g})$ & $0.74^{* * *}$ \\
Foliage dry matter $(\%)$ & $0.23 \mathrm{~ns}$ \\
Bulb length (mm) & $0.62^{* * *}$ \\
Bulb diameter (mm) & $0.66^{\star * *}$ \\
Bulb fresh weight $(\mathrm{g})$ & $0.79^{* * *}$ \\
Bulb dry matter (\%) & $0.20 \mathrm{~ns}$ \\
Cloves no. bulb-1 & $-0.05 \mathrm{~ns}$ \\
Average clove weight $(\mathrm{g})$ & $0.31 \mathrm{~ns}$ \\
\hline
\end{tabular}

ns: correlation insignificant;

*: correlation is significant at $P \leq 0.05$;

${ }^{* *}$ : correlation is significant at $P \leq 0.01$;

***: correlation is significant at $P \leq 0.001$. 
TABLE 4. Pair-wise Euclidean distances between 27 garlic cultivars and ecotypes based on 14 morphological characters.

\begin{tabular}{|c|c|c|c|c|c|c|c|c|c|c|c|c|}
\hline Genotype & $\begin{array}{l}\frac{\overrightarrow{0}}{\tilde{D}} \\
\frac{\tilde{D}}{\tilde{D}}\end{array}$ & 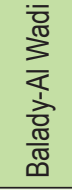 & $\begin{array}{l}\bar{\Xi} \\
\frac{0}{0}\end{array}$ & $\begin{array}{l}\stackrel{L}{0} \\
\stackrel{0}{0} \\
\end{array}$ & $\begin{array}{l}\frac{\infty}{\Phi} \\
\frac{0}{0} \\
\frac{0}{U}\end{array}$ & 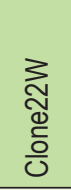 & 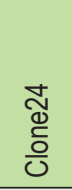 &  & 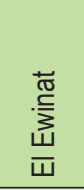 & 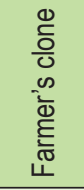 &  & 㶓 \\
\hline Balady & 0 & & & & & & & & & & & \\
\hline Balady-Al Wadi & 1.82 & 0.00 & & & & & & & & & & \\
\hline Clone-1 & 2.98 & 2.16 & 0.00 & & & & & & & & & \\
\hline Clone-5 & 1.57 & 1.92 & 3.46 & 0.00 & & & & & & & & \\
\hline Clone-18 & 2.67 & 1.87 & 1.40 & 3.31 & 0.00 & & & & & & & \\
\hline Clone-22-W & 1.33 & 2.00 & 3.44 & 1.41 & 3.28 & 0.00 & & & & & & \\
\hline Clone-24 & 3.39 & 1.88 & 2.24 & 3.38 & 2.35 & 3.27 & 0.00 & & & & & \\
\hline Clone-25 & 1.34 & 2.38 & 3.44 & 2.19 & 2.91 & 2.19 & 4.10 & 0.00 & & & & \\
\hline El Ewinat & 1.89 & 2.84 & 4.31 & 1.40 & 4.12 & 1.57 & 4.29 & 2.43 & 0.00 & & & \\
\hline Farmer's clone & 2.67 & 4.03 & 4.87 & 2.93 & 4.91 & 3.06 & 5.53 & 2.67 & 2.44 & 0.00 & & \\
\hline Salaqus-3 & 1.04 & 1.96 & 2.95 & 2.02 & 2.45 & 1.76 & 3.48 & 1.54 & 2.29 & 3.35 & 0.00 & \\
\hline Aswan & 2.31 & 3.05 & 3.09 & 3.42 & 2.91 & 3.23 & 4.37 & 2.03 & 3.82 & 3.45 & 2.35 & 0.00 \\
\hline Borg El-Arab & 8.77 & 7.50 & 6.43 & 9.15 & 6.42 & 9.12 & 6.21 & 9.15 & 10.16 & 11.00 & 8.56 & 8.51 \\
\hline El Behera & 1.75 & 2.39 & 3.09 & 2.76 & 2.50 & 2.60 & 3.62 & 1.96 & 3.29 & 3.80 & 1.50 & 1.89 \\
\hline El Fayoum-1 & 1.78 & 2.11 & 3.16 & 1.84 & 3.28 & 1.49 & 3.29 & 2.28 & 1.96 & 2.61 & 2.30 & 3.07 \\
\hline El Fayoum-2 & 1.54 & 1.72 & 2.74 & 1.64 & 2.42 & 1.89 & 2.98 & 1.91 & 2.58 & 3.31 & 1.82 & 2.53 \\
\hline Egaseed-1A & 5.65 & 5.91 & 5.79 & 5.94 & 5.63 & 6.25 & 6.42 & 5.89 & 6.62 & 6.99 & 5.31 & 5.06 \\
\hline Egaseed-1B & 6.76 & 6.98 & 6.57 & 7.19 & 6.33 & 7.55 & 7.47 & 6.84 & 7.88 & 7.91 & 6.55 & 5.72 \\
\hline Egaseed-2 & 6.42 & 6.55 & 5.94 & 6.87 & 5.64 & 7.20 & 6.87 & 6.22 & 7.81 & 7.64 & 6.32 & 5.57 \\
\hline Egaseed-3 & 5.44 & 6.19 & 6.32 & 5.67 & 6.05 & 6.18 & 7.24 & 5.29 & 6.15 & 5.89 & 5.33 & 4.72 \\
\hline Sids-40-R.S. & 6.95 & 7.03 & 6.39 & 7.43 & 6.30 & 7.74 & 7.33 & 7.14 & 8.26 & 8.32 & 6.78 & 5.93 \\
\hline Sids-40-Ayat & 5.72 & 5.84 & 5.67 & 5.68 & 5.54 & 6.35 & 6.41 & 5.81 & 6.57 & 6.69 & 5.66 & 5.18 \\
\hline Clone-21 & 4.82 & 5.55 & 5.76 & 5.52 & 5.34 & 5.61 & 6.36 & 4.97 & 5.84 & 5.86 & 4.66 & 4.19 \\
\hline Clone-22-R & 5.98 & 6.62 & 6.64 & 6.52 & 6.25 & 6.78 & 7.41 & 5.95 & 6.94 & 6.74 & 5.87 & 5.03 \\
\hline Al Ayat-1 & 5.85 & 6.57 & 6.53 & 6.16 & 6.27 & 6.55 & 7.42 & 5.90 & 6.42 & 6.41 & 5.63 & 5.24 \\
\hline Bany gonamy & 6.52 & 6.51 & 6.34 & 6.56 & 6.25 & 7.19 & 6.87 & 6.64 & 7.50 & 7.51 & 6.51 & 5.92 \\
\hline Salaqus & 5.54 & 6.22 & 6.20 & 5.76 & 6.07 & 6.28 & 7.06 & 5.59 & 6.28 & 5.92 & 5.57 & 4.88 \\
\hline
\end{tabular}

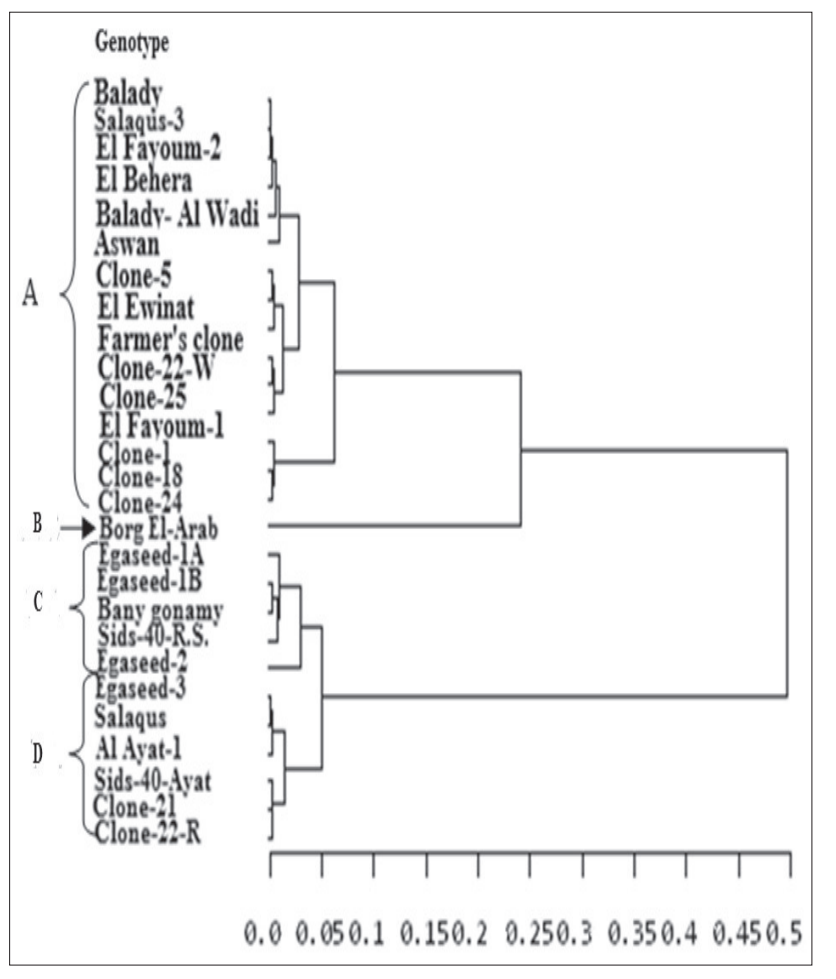

Clone-24, while group “1-B” includes Borg El-Arab genotype. On the other hand, the second main cluster covered the rest of genotypes, which have purple bulb, and is clustered into two groups; group "C", involves Egaseed-1A, Egaseed1B, Bany gonamy, Sids-40-R.S., and Egaseed-2, while group "D" included Egaseed-3, Salaqus, Al Ayat-1, Sids-40-Ayat, Clone-21 and Clone-22-R (Figure 2).

The results of the present study revealed that clustering of studied genotypes does not correspond to the geographical origin, where genotypes collected from the north and south of Egypt were combined into one cluster, while clustering of the studied landraces was clearly distinguished between purple and white bulb genotypes. Cluster analysis depending on morphological characters performed on genetic resources gives initial signal to understand the germplasm and select the potential material among a large-scale of landraces with high efficiency.

FIGURE 2. Dendrogram generated by Ward's method of cluster analysis based on morphological characters of studied garlic landraces. 
TABLE 4. Continued.

\begin{tabular}{|c|c|c|c|c|c|c|c|c|c|c|c|c|c|c|c|}
\hline Genotype & 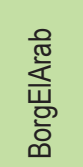 & 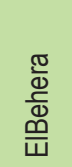 & 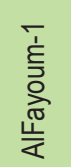 & 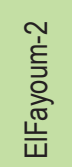 & 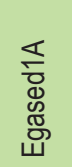 &  & $\begin{array}{l}\text { ్ㅀ } \\
\mathbb{8} \\
\mathbb{D} \\
\text { ర్ }\end{array}$ & $\begin{array}{l}\text { ల్ర } \\
\mathbb{\$} \\
\mathbb{D} \\
\mathbb{J} \\
\text { W }\end{array}$ & 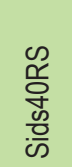 &  & $\begin{array}{l}\bar{Ð} \\
\stackrel{\bar{\Xi}}{\cup}\end{array}$ & 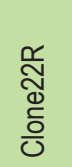 &  & 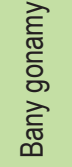 & 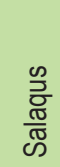 \\
\hline Borg El-Arab & 0.00 & & & & & & & & & & & & & & \\
\hline El Behera & 8.05 & 0.00 & & & & & & & & & & & & & \\
\hline El Fayoum-1 & 9.13 & 2.90 & 0.00 & & & & & & & & & & & & \\
\hline El Fayoum-2 & 8.25 & 1.78 & 1.93 & 0.00 & & & & & & & & & & & \\
\hline Egaseed-1A & 8.52 & 4.38 & 6.55 & 5.22 & 0.00 & & & & & & & & & & \\
\hline Egaseed-1B & 8.57 & 5.55 & 7.69 & 6.27 & 2.72 & 0.00 & & & & & & & & & \\
\hline Egaseed-2 & 7.89 & 5.28 & 7.34 & 5.72 & 4.44 & 4.52 & 0.00 & & & & & & & & \\
\hline Egaseed-3 & 10.26 & 4.52 & 6.31 & 5.02 & 2.87 & 3.19 & 4.51 & 0.00 & & & & & & & \\
\hline Sids-40-R.S. & 7.83 & 5.84 & 7.97 & 6.56 & 3.16 & 1.81 & 4.27 & 4.19 & 0.00 & & & & & & \\
\hline Sids-40-Ayat & 8.71 & 4.90 & 6.45 & 4.95 & 2.99 & 2.64 & 4.10 & 2.54 & 3.14 & 0.00 & & & & & \\
\hline Clone-21 & 9.14 & 3.52 & 5.84 & 4.72 & 2.59 & 3.41 & 4.90 & 2.84 & 4.24 & 4.00 & 0.00 & & & & \\
\hline Clone-22-R & 9.67 & 4.77 & 6.89 & 5.62 & 2.90 & 2.27 & 4.75 & 2.15 & 3.60 & 3.23 & 1.95 & 0.00 & & & \\
\hline Al Ayat-1 & 10.21 & 4.91 & 6.59 & 5.51 & 3.02 & 3.13 & 5.54 & 2.08 & 4.53 & 3.34 & 2.73 & 2.14 & 0.00 & & \\
\hline Bany gonamy & 8.47 & 5.46 & 7.24 & 5.74 & 2.90 & 2.80 & 3.79 & 3.26 & 3.06 & 2.00 & 3.99 & 3.39 & 4.06 & 0.00 & \\
\hline Salaqus & 9.96 & 4.68 & 6.28 & 5.05 & 2.93 & 2.94 & 4.54 & 1.28 & 3.94 & 2.30 & 2.77 & 1.98 & 2.03 & 2.78 & 0.00 \\
\hline
\end{tabular}

TABLE 5. Name, sequence, number of amplifications, and polymorphic ISSR products using the four studied primers for 27 garlic genotypes.

\begin{tabular}{lcccc}
\hline Name & Sequence $\left(5^{\prime}\right.$ to $\left.3^{\prime}\right)$ & No. of amplification products (a) & No. of polymorphic products (b) & Polymorphism (b/a \%) \\
\hline UBC-812 & $(\mathrm{GA})_{8} \mathrm{~A}$ & 19 & 19 & 100.00 \\
UBC-817 & $(\mathrm{CA})_{8} \mathrm{~A}$ & 10 & 10 & 100.00 \\
UBC-825 & $(\mathrm{AC})_{7} T^{\prime}$ & 13 & 12 & 92.31 \\
UBC-842 & $(\mathrm{CT})_{8} \mathrm{Y}^{\$} \mathrm{G}$ & 13 & 13 & 100.00 \\
\hline Total & & 55 & 54 & 98.18 \\
\hline
\end{tabular}

$\$: Y=G / C$.

\section{Genetic diversity assessment based on ISSR molecular markers}

Four of five ISSR primers were regenerated polymorphism in all DNA templates (Table 5). Where three of them (UBC-812, UBC-817 and UBC-842 primers) showed the highest polymorphism $(100 \%)$. The fourth ISSR primer (UBC825 ) showed $92.31 \%$ polymorphism. The regenerated bands of the individual primer were ranged from 1 to 9 bands, depending on primer and DNA sample. PCR products of the four ISSR primers used at the 27 garlic genotypes were separated by size resulted 55 amplified fragments, 54 of them were polymorphic ( $98.18 \%$ polymorphism) in one or other of studied genotypes. The PCR profiles (Figures 3-6) of the four ISSR primers showed clearly the polymorphism among studied genotypes.

Similarity coefficient (Table 6), based on pairwise comparison using ISSR data, showed that Balady, Balady-Al Wadi, Clone-1 and Clone-24 were genetically similar (similarity coefficient $=1$ ). Also, Clone- 21 and Salaqus presented $100 \%$ genetic similarity.

The similarity coefficient of the other studied genotypes ranged from 0.08 to 0.96 , suggesting a broad genetic base of Egyptian garlic genotypes.

Dendrogram obtained from cluster analysis (Figure 7) of ISSR data which generated using Jaccard's coefficient, illustrated that the studied genotypes were clustered into two main clusters. The first main cluster, including twenty-six genotypes, which were grouped into three groups, "A", "B", and "C". The second main cluster includes group " $\mathrm{D}$ ", and contained one genotype; Clone- 5 with similar coefficient (ranged from 0.08 to 0.18 ). This proved that Clone- 5 is genetically different from the other studied genotypes.

Group "A" includes white bulb genotypes; Balady, BaladyAl Wadi, Clone-1, Clone-18, Clone-22-W, Clone-24, Clone25, El Ewinat, Farmer's clone, Salaqus-3, Aswan, Borg El-Arab, El Behera, El Fayoum 1 and El Fayoum 2. The lowest similarity coefficient was found to be 0.45 , and the highest genetically variation within "A" group's genotypes was scored between Farmer's clone and Clone-22-W (Table 6; Figure 7).

Group "B" consists of two clones of Egaseed-1 cultivar, Egaseed-1A and Egaseed-1B, which had purple bulb and 0.88 similarity coefficient (Table 6).

Finally, group " $\mathrm{C}$ " involved nine genotypes which had purple bulb too; Egaseed-2, Egaseed-3, Sids-40-R.S., Sids40-Ayat, Clone-21, Salaqus, Clone-22-R, Bany gonamy and Al Ayat-1. The lowest similarity coefficient (0.34) was scored between Egaseed-2 and both of Egaseed-3 and Al Ayat-1.

\section{Discussion}

Estimated values of the correlation coefficients for the pairs of the thirteen studied characters with the total yield revealed highly significant positive correlation $(P \leq 0.001)$ 


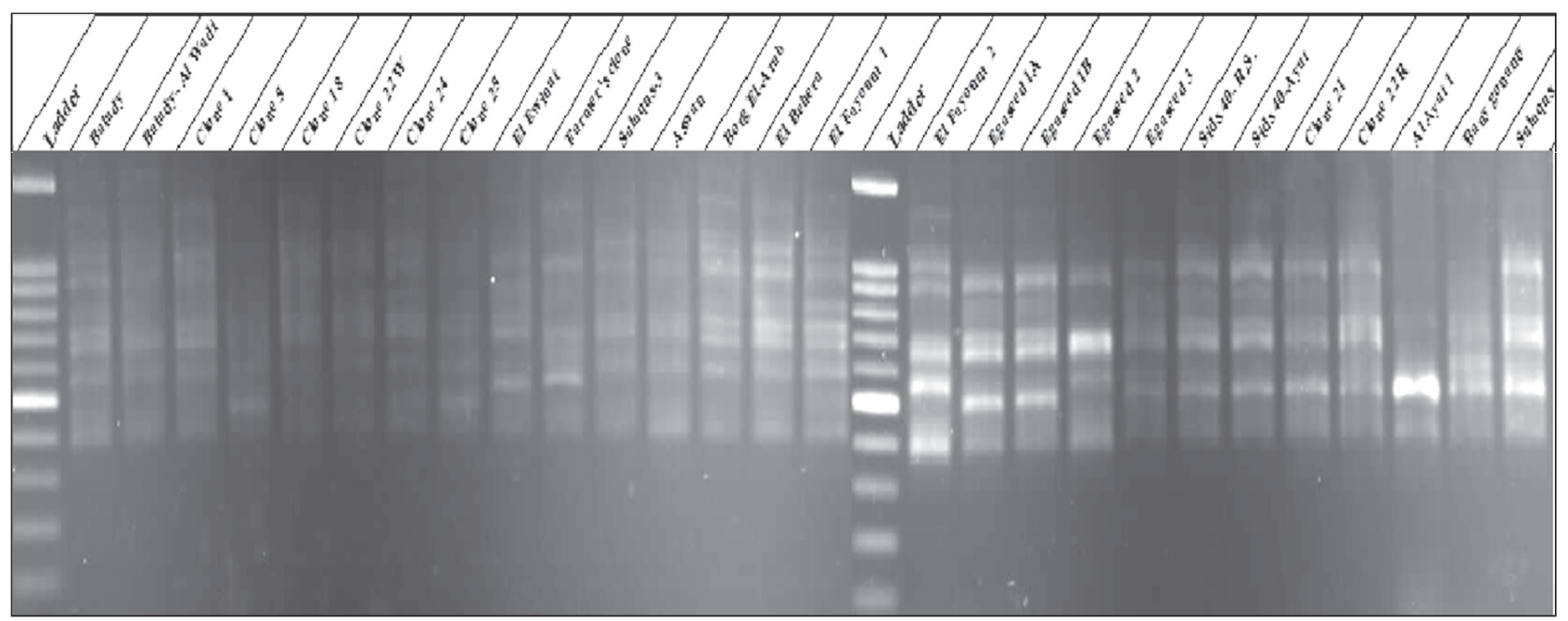

FIGURE 3. PCR profile of 27 garlic genotypes generated by UBC-812 ISSR primer. Lanes from left to right: Ladder (DNA marker 100 bp), Balady, Balady-Al Wadi, Clone-1, Clone-5, Clone-18, Clone-22-W, Clone-24, Clone-25, El Ewinat, Farmer's clone, Salaqus-3, Aswan, Borg El-Arab, El Behera, El Fayoum-1, Ladder, El Fayoum-2, Egaseed-1A, Egaseed-1B, Egaseed-2, Egaseed-3, Sids-40-R.S., Sids-40-Ayat, Clone-21, Clone-22-R, Al Ayat-1, Bany gonamy and Salaqus.

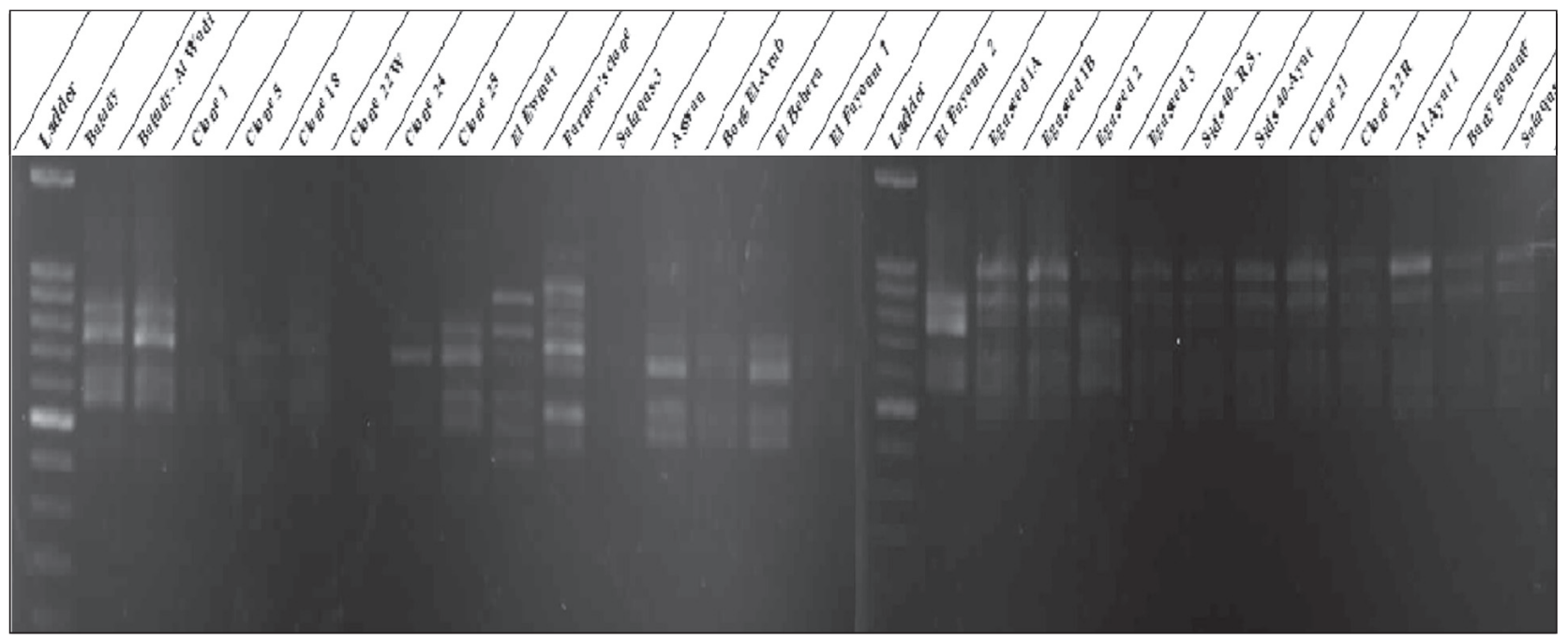

FIGURE 4. PCR profile in 27 garlic genotypes generated by UBC-817 ISSR primer. Lanes from left to right: Ladder (DNA marker 100 bp), Balady, Balady-Al Wadi, Clone-1, Clone-5, Clone-18, Clone-22-W, Clone-24, Clone-25, El Ewinat, Farmer's clone, Salaqus-3, Aswan, Borg El-Arab, El Behera, El Fayoum-1, Ladder, El Fayoum-2, Egaseed-1A, Egaseed-1B, Egaseed-2, Egaseed-3, Sids-40-R.S., Sids-40-Ayat, Clone-21, Clone-22-R, Al Ayat-1, Bany gonamy and Salaqus.



FIGURE 5. PCR profile in 27 garlic genotypes generated by UBC-825 ISSR primer. Lanes from left to right: Ladder (DNA marker 100 bp), Balady, Balady-Al Wadi, Clone-1, Clone-5, Clone-18, Clone-22-W, Clone-24, Clone-25, El Ewinat, Farmer's clone, Salaqus-3, Aswan, Borg El-Arab, El Behera, El Fayoum-1, Ladder, El Fayoum-2, Egaseed-1A, Egaseed-1B, Egaseed-2, Egaseed-3, Sids-40-R.S., Sids-40-Ayat, Clone-21, Clone-22-R, Al Ayat-1, Bany gonamy and Salaqus. 
TABLE 6. Similarity coefficient determined from ISSR analysis, using four primers in 27 garlic landraces.

\begin{tabular}{|c|c|c|c|c|c|c|c|c|c|c|c|c|c|}
\hline Genotype & $\begin{array}{l}\frac{\lambda}{\mathbb{D}} \\
\frac{\mathbb{\pi}}{\mathbb{N}} \\
\infty\end{array}$ &  & $\begin{array}{l}\bar{\Phi} \\
\bar{\delta} \\
\bar{U}\end{array}$ & $\begin{array}{l}\stackrel{\llcorner}{ \pm} \\
\stackrel{0}{0}\end{array}$ & $\begin{array}{l}\frac{\infty}{\Phi} \\
\frac{0}{0} \\
U\end{array}$ & 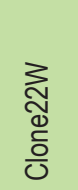 &  & 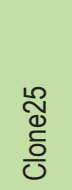 &  & 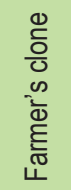 & $\begin{array}{l}\text { D } \\
\frac{\mathscr{D}}{D} \\
\frac{\mathbb{D}}{\mathbb{N}} \\
\mathscr{N}\end{array}$ & 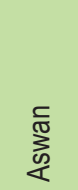 & $\begin{array}{l}\text { 윰 } \\
\text { 这 } \\
\text { 잏 } \\
0\end{array}$ \\
\hline Balady & 1.00 & & & & & & & & & & & & \\
\hline Balady-AI Wadi & 1.00 & 1.00 & & & & & & & & & & & \\
\hline Clone-1 & 1.00 & 1.00 & 1.00 & & & & & & & & & & \\
\hline Clone-5 & 0.13 & 0.13 & 0.13 & 1.00 & & & & & & & & & \\
\hline Clone-18 & 0.96 & 0.96 & 0.96 & 0.13 & 1.00 & & & & & & & & \\
\hline Clone-22-W & 0.63 & 0.63 & 0.63 & 0.18 & 0.61 & 1.00 & & & & & & & \\
\hline Clone-24 & 1.00 & 1.00 & 1.00 & 0.13 & 0.96 & 0.63 & 1.00 & & & & & & \\
\hline Clone-25 & 0.89 & 0.89 & 0.89 & 0.18 & 0.86 & 0.54 & 0.89 & 1.00 & & & & & \\
\hline El Ewinat & 0.89 & 0.89 & 0.89 & 0.09 & 0.93 & 0.55 & 0.89 & 0.79 & 1.00 & & & & \\
\hline Farmer's clone & 0.71 & 0.71 & 0.71 & 0.13 & 0.74 & 0.45 & 0.71 & 0.63 & 0.74 & 1.00 & & & \\
\hline Salaqus-3 & 0.92 & 0.92 & 0.92 & 0.14 & 0.89 & 0.68 & 0.92 & 0.81 & 0.82 & 0.70 & 1.00 & & \\
\hline Aswan & 0.70 & 0.70 & 0.70 & 0.17 & 0.68 & 0.90 & 0.70 & 0.61 & 0.62 & 0.47 & 0.69 & 1.00 & \\
\hline Borg El-Arab & 0.96 & 0.96 & 0.96 & 0.14 & 0.93 & 0.59 & 0.96 & 0.92 & 0.86 & 0.68 & 0.88 & 0.67 & 1.00 \\
\hline El Behera & 0.93 & 0.93 & 0.93 & 0.13 & 0.96 & 0.59 & 0.93 & 0.83 & 0.90 & 0.77 & 0.86 & 0.66 & 0.89 \\
\hline El Fayoum-1 & 0.96 & 0.96 & 0.96 & 0.14 & 0.93 & 0.65 & 0.96 & 0.85 & 0.86 & 0.68 & 0.96 & 0.73 & 0.92 \\
\hline El Fayoum-2 & 0.96 & 0.96 & 0.96 & 0.14 & 0.93 & 0.59 & 0.96 & 0.85 & 0.86 & 0.68 & 0.88 & 0.67 & 0.92 \\
\hline Egaseed-1A & 0.32 & 0.32 & 0.32 & 0.11 & 0.32 & 0.21 & 0.32 & 0.37 & 0.35 & 0.32 & 0.31 & 0.26 & 0.33 \\
\hline Egaseed-1B & 0.32 & 0.32 & 0.32 & 0.10 & 0.31 & 0.20 & 0.32 & 0.36 & 0.34 & 0.31 & 0.30 & 0.26 & 0.32 \\
\hline Egaseed-2 & 0.38 & 0.38 & 0.38 & 0.14 & 0.41 & 0.19 & 0.38 & 0.39 & 0.37 & 0.37 & 0.36 & 0.25 & 0.39 \\
\hline Egaseed-3 & 0.33 & 0.33 & 0.33 & 0.11 & 0.32 & 0.25 & 0.33 & 0.34 & 0.32 & 0.29 & 0.35 & 0.27 & 0.34 \\
\hline Sids-40-R.S. & 0.34 & 0.34 & 0.34 & 0.10 & 0.33 & 0.26 & 0.34 & 0.35 & 0.33 & 0.33 & 0.36 & 0.29 & 0.35 \\
\hline Sids-40-Ayat & 0.41 & 0.41 & 0.41 & 0.10 & 0.39 & 0.29 & 0.41 & 0.42 & 0.39 & 0.39 & 0.43 & 0.31 & 0.42 \\
\hline Clone-21 & 0.41 & 0.41 & 0.41 & 0.10 & 0.39 & 0.26 & 0.41 & 0.42 & 0.39 & 0.39 & 0.43 & 0.28 & 0.42 \\
\hline Clone-22-R & 0.28 & 0.28 & 0.28 & 0.08 & 0.27 & 0.27 & 0.28 & 0.29 & 0.27 & 0.24 & 0.29 & 0.25 & 0.29 \\
\hline Al Ayat-1 & 0.23 & 0.23 & 0.23 & 0.11 & 0.23 & 0.25 & 0.23 & 0.24 & 0.23 & 0.23 & 0.24 & 0.27 & 0.24 \\
\hline Bany gonamy & 0.38 & 0.38 & 0.38 & 0.09 & 0.40 & 0.24 & 0.38 & 0.35 & 0.40 & 0.37 & 0.39 & 0.26 & 0.35 \\
\hline Salaqus & 0.41 & 0.41 & 0.41 & 0.10 & 0.39 & 0.26 & 0.41 & 0.42 & 0.39 & 0.39 & 0.43 & 0.28 & 0.42 \\
\hline
\end{tabular}

TABLE 6. Continued.

\begin{tabular}{|c|c|c|c|c|c|c|c|c|c|c|c|c|c|c|}
\hline Genotype & 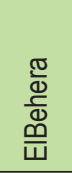 & 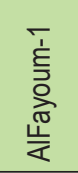 & 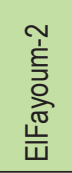 & 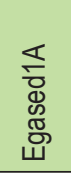 & 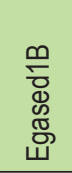 & 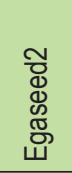 &  &  &  & $\begin{array}{l}\bar{\mho} \\
\text { ठ․ }\end{array}$ & 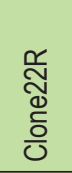 & 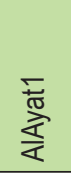 & 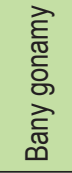 & 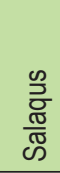 \\
\hline El Behera & 1.00 & & & & & & & & & & & & & \\
\hline El Fayoum-1 & 0.89 & 1.00 & & & & & & & & & & & & \\
\hline El Fayoum-2 & 0.89 & 0.92 & 1.00 & & & & & & & & & & & \\
\hline Egaseed-1A & 0.34 & 0.33 & 0.33 & 1.00 & & & & & & & & & & \\
\hline Egaseed-1B & 0.33 & 0.32 & 0.32 & 0.88 & 1.00 & & & & & & & & & \\
\hline Egaseed-2 & 0.39 & 0.39 & 0.39 & 0.37 & 0.44 & 1.00 & & & & & & & & \\
\hline Egaseed-3 & 0.35 & 0.34 & 0.34 & 0.45 & 0.44 & 0.34 & 1.00 & & & & & & & \\
\hline Sids-40-R.S. & 0.36 & 0.35 & 0.35 & 0.41 & 0.48 & 0.52 & 0.74 & 1.00 & & & & & & \\
\hline Sids-40-Ayat & 0.42 & 0.42 & 0.42 & 0.40 & 0.47 & 0.55 & 0.66 & 0.89 & 1.00 & & & & & \\
\hline Clone-21 & 0.42 & 0.42 & 0.42 & 0.40 & 0.47 & 0.59 & 0.66 & 0.89 & 0.93 & 1.00 & & & & \\
\hline Clone-22-R & 0.26 & 0.29 & 0.29 & 0.30 & 0.33 & 0.45 & 0.56 & 0.80 & 0.77 & 0.77 & 1.00 & & & \\
\hline Al Ayat-1 & 0.25 & 0.24 & 0.24 & 0.36 & 0.35 & 0.34 & 0.63 & 0.74 & 0.66 & 0.66 & 0.62 & 1.00 & & \\
\hline Bany gonamy & 0.39 & 0.38 & 0.38 & 0.30 & 0.36 & 0.54 & 0.50 & 0.69 & 0.72 & 0.77 & 0.63 & 0.55 & 1.00 & \\
\hline Salaqus & 0.42 & 0.42 & 0.42 & 0.40 & 0.47 & 0.59 & 0.66 & 0.89 & 0.93 & 1.00 & 0.77 & 0.66 & 0.77 & 1.00 \\
\hline
\end{tabular}




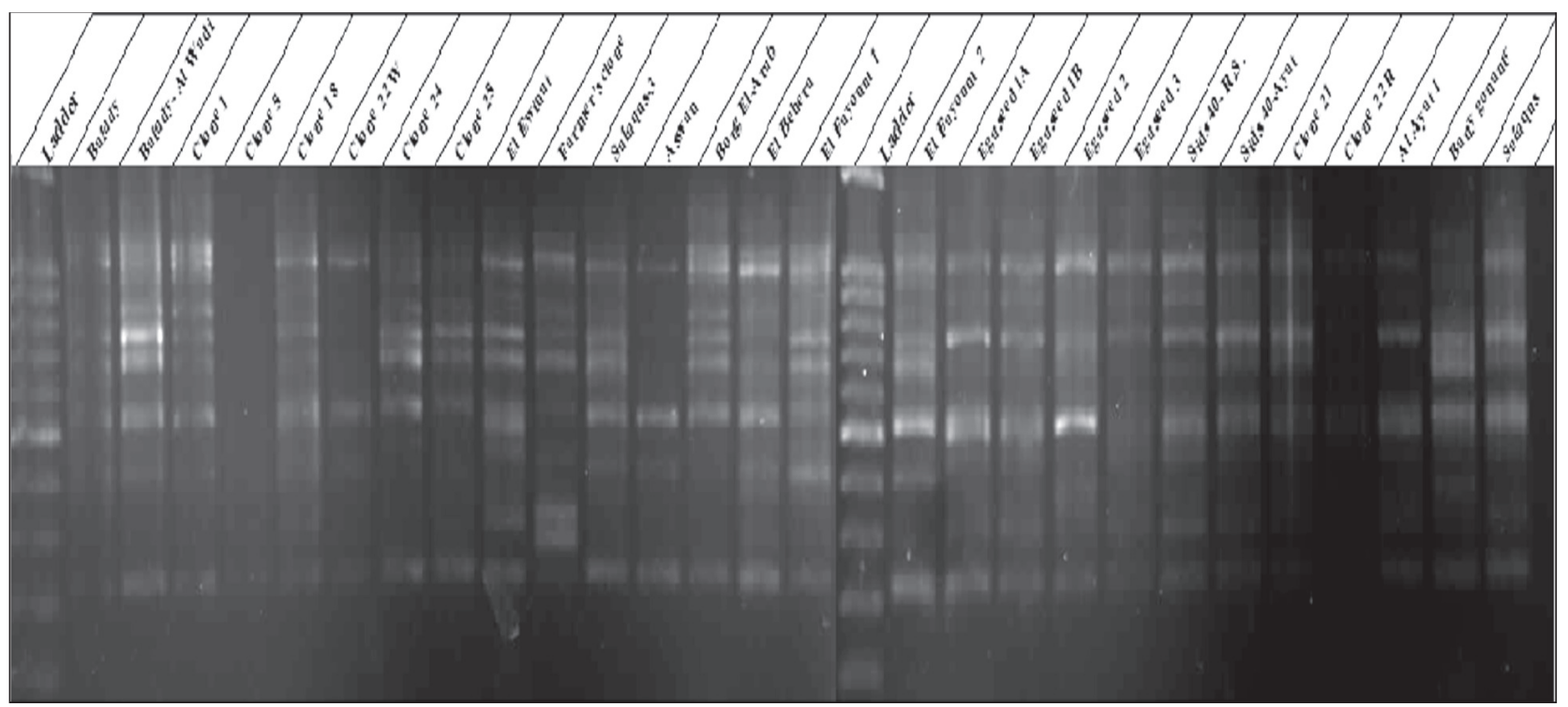

FIGURE 6. PCR profile in 27 garlic genotypes generated by UBC-842 ISSR primer. Lanes from left to right: Ladder (DNA marker 100 bp), Balady, Balady-Al Wadi, Clone-1, Clone-5, Clone-18, Clone-22-W, Clone-24, Clone-25, El Ewinat, Farmer's clone, Salaqus-3, Aswan, Borg El-Arab, El Behera, El Fayoum-1, Ladder, El Fayoum-2, Egaseed-1A, Egaseed-1B, Egaseed-2, Egaseed-3, Sids-40-R.S., Sids-40-Ayat, Clone-21, Clone-22-R, Al Ayat-1, Bany gonamy and Salaqus.



FIGURE 7. Dendrogram constructed from similarity coefficients and showing the clustering of 27 garlic landraces using ISSR markers. 
among the total yield (ton ha-1), leaf width (0.62), plant fresh weight (0.99), foliage fresh weight (0.74), and bulb traits, i.e., length (0.62), diameter (0.66) and fresh weight (0.79) throughout the two growing seasons. Choosing genotypes with high levels of these characteristics will guarantee higher yield. The high positive significant correlation between the total fresh yield and other vegetative growth and bulb characteristics indicated that the selection for one or more of these characters will be the indicator for high total yield and higher productivity. Certainly if there is bigger bulb diameter or higher bulb weight, higher yield could be expected. Cloves number per bulb $(\mathrm{r}=-0.05)$ has insignificant negative correlation with total yield, which means that genotypes with high cloves number may produce lower yield. Previous studies have considered the relationship between total yield and some phenotypic characteristics. Panthee et al. (2006) studied growth characters of 179 garlic ecotypes, which were collected from different regions of Nepal. They reported that total yield of garlic has a positive correlation with germination speed, bulbing period, duration to maturity, plant height, leaves number, bulb weight, bulb diameter, cloves number, and clove diameter. Several previous studies reported the importance of various morphological characteristics on the final yield of garlic. They also reported that plant height and plant fresh weight correlated positively with garlic yielding. In the present study it was found that bulb yield has strongly positive correlation with bulb weight and diameter (Abu ElOyun, 2010; Dawood, 2011; Islam et al., 2004; Wang et al., 2014; Esho, 2015).

Cluster analysis depending on morphological characters performed on genetic resources gives initial signal to understand the germplasm and to select the potential material among a large scale of landraces and cultivars with high efficiency. The results of the present study revealed that clustering of the studied genotypes did not correspond to the geographical origin. The collected genotypes from north and south of Egypt combined into one cluster. However, clustering of the studied landraces was clearly distinguished between purple and white bulb genotypes. Pooler and Simon (1993) conducted an experiment to evaluate 110 phenotypically diverse clones of cultivated (A. sativum) and wild garlic (A. longicuspis). They reported that different ecotypes had a great morphological variation in bulb and leaf size, color and shape, scape presence and height, and flower color, fertility, and bulbil (top-set) development of inflorescence. Moreover, the studied 110 clones were placed into 17 distinct isozyme groups which were associated with morphological traits. Lallemand et al. (1997) evaluated 65 garlic accessions collected from 25 Asian countries, clustered in six groups based on morphological and physiological traits. Likewise, 179 garlic accessions collected from various parts of Nepal have been clustered in three main groups according to their morphological traits (Panthee et al., 2006). Results of the present study are in harmony with those of Jabbes et al. (2011) and Panthee et al. (2006), who found no relationship between genotypes clustering and geographical location. However, Mohammadi et al. (2014) reported that 16 Iranian garlic accessions were clustered into four distinct major clusters with respect of geographical origin. Wang et al. (2014) studied diversity of 212 Chinese garlic accessions, which were organized in two main clusters and five sub-clusters using 29 quantitative and qualitative morphological characters. Our results indicated that germplasm cluster analysis can distinguish all germplasm and will make breeders comprehensively understand the genetic background of them and more easily select the target genotype with high yield and different component traits from different groups. These results were previously confirmed in several studies (Lallemand et al., 1997; Panthee et al., 2006; Jabbes et al., 2011).

ISSR markers have been used to fingerprint and genetic diversity detected in different plant species and cultivars (Nagaoka and Ogihara, 1997; Wolf et al., 1998; Nagaraju et al., 2002; Al-Humaid et al., 2004; Qijiang et al., 2007; Son et al., 2012). ISSR technique was reported to be used successfully for molecular characterization and genetic diversity assessment among closely related cultivars, since ISSR primers target the microsatellite regions and need no sequence information for primer synthesis (Jabbes et al., 2011; Fang and Roose, 1997; Joshi et al., 2000; Sarwat, 2012). ISSR marker efficiency was compared with RAPD markers in garlic genetic diversity assessment and has been mentioned in previous researches. Al-Otayk et al. (2008) used 8 RAPD primers and 7 ISSR primers for genetic diversity assessment among Egyptian, Chinese and Elephant garlic cultivars, in addition to six Chinese lines. RAPD primers were presented $6.45 \%$ polymorphism, while ISSR primers showed $21.43 \%$ polymorphism among Chinese lines. Moreover, the cultivars and lines of garlic which were clustered into three groups using RAPD markers, clustered into five groups using ISSR markers, which indicates that ISSR technique was more specific and can detect the variation among closely genetically genotypes.

In the same direction Mukherjee et al. (2013) used 12 RAPD primers and 11 ISSR primers to study the genetic relationship among five Allium species, 5 garlic (A. sativum) cultivars, 8 onions (A. cepa) cultivars, 4 leeks (A. porrum) cultivars, 1 chives (A. tuberosum) garlic and 1 Jungli piyaz (A. stracheyi). They reported that $63.77 \%$ of total polymorphism was found among species, and $36.23 \%$ was found within species using RAPD markers, while ISSR markers showed $54.86 \%$ polymorphism among species, and $45.86 \%$ was found within species. Jabbes et al. (2011) studied diversity in 35 garlic accessions, collected from Tunisia and France, using seven ISSR primers. Eighty-four polymorphic bands were regenerated. Tunisian accessions had $54.3 \%$ from the polymorphic bands, while French clones had $46.7 \%$ from them; this may reflect larger genetic diversity for Tunisian populations. Chen et al. (2014) recorded 75\% polymorphism among 39 garlic accessions using seventeen ISSR primers. They reported that the studied 39 garlic accessions have been clustered into three groups without the relationship between banding patterns and geographical origins.

In Egypt, El-Nagar and El-Zohiri (2015) used six ISSR primers to study the genetic diversity among five garlic genotypes; Balady, Sids-40, Chinese, Italian and Brazilian. Each primer generated bands with two or three different garlic genotypes, except one primer which generated $25 \%$ of total polymorphic bands with all studied cultivars. The results indicated the presence of polymorphism at a high level among Egyptian garlic genotypes.

The genetic diversity among four Egyptian garlic cultivars (Balady, Sids-40, Egaseed-1, Egaseed-2) have been detected by Badran (2015) who used five ISSR primers. Polymorphism at a value of $56.67 \%$ has been recorded, with adequate distinction among the four tested garlic cultivars. Mondal et al. (2008) confirmed that ISSR revealed higher polymorphism $(74.5 \%)$ than RAPD (47.1\%) in peanut genotypes.

In conclusion, regarding similarity coefficient and cluster analysis based on morphological characters and molecu- 
lar markers, it is clear that morphological characters can be signed to genetic diversity even if it is not that much clear and affected by plant physiological status and environmental conditions. Therefore, the morphological character is not stable, unlike molecular markers assay. The present study proved that characterization and evaluation of the Egyptian landraces at the molecular level and field performance should be followed by breeding programs to improve qualities and quantities of garlic landraces under Borg El-Arab conditions and in similar regions.

\section{Acknowledgments}

My sincere gratitude to Alexandria University, Egypt, for introducing all facilities needed for this study. I sincerely appreciate all kind of help supported by Dr. Ismail Khatab, Professor of Genetics, Kafr Elsheikh University, and Dr. Gaber Atia, Professor at Laboratory of Bioprocess Development Department, City for Scientific Research and Technology Applications, New Borg El-Arab City, Alexandria, Egypt for their help and support during this study. We thank Taif University Researchers Supporting Project number TURSP-2020/13, Taif University, Taif, Saudi Arabia.

\section{Funding statement}

The present work was partially supported by Faculty of Agriculture, Alexandria University, Egypt.

\section{Conflict of interest}

The authors declare that there is no conflict of interest.

\section{References}

Abdel-halim, H.H. (2014). Garlic germplasm resources evaluation and somaclonal mutagenesis technology study based on gamma radiation and EMS treatment on callus. Ph.D. thesis (Institute of Vegetables and Flowers, Chinese Academy of Agricultural Science).

Abu El-Oyun, D.I. (2010). The performance of some Egyptian garlic strains under Assiut conditions. M.Sc. thesis (Assiut University, Faculty of Agriculture).

Al-Humaid, A., Motawei, M.I., Abdalla, M.Y., and Mana, F. (2004). Detection of genetic variation and Fusarium resistance in turfgrass genotypes using PCR-based markers (ISSR and SCAR). J. Food Agric. Environm. 2(3), 225-229.

Al-Otayk, S., El-Shinawy, M.Z., and Motawei, M.I. (2008). Variation in productive characteristics and diversity assessment of garlic cultivars and lines using DNA markers. Meth. Env. Arid Land Agric. Sci. 20(1), 63-79 https://doi.org/10.4197/met.20-1.4.

Badran, A.E. (2015). Comparative analysis of some garlic varieties under drought stress conditions. J. Agric. Sci. 7(10), 271-280. https://doi.org/10.5539/jas.v7n10p271.

Barad, Y.M., Kathiria, K.B., and Modha, K.G. (2012). Correlation and path coefficient studies in garlic (Allium sativum L.) over different environments. Veg. Sci. 39(1), 79-82.

Bekheet, S.A. (2006). A synthetic seed method through encapsulation of in vitro proliferated bulblets of garlic (Allium sativum L.). Arab J. Biotechnol. 9, 415-426.

Chen, S., Chen, W., Shen, X., Yang, Y., Qi, F., Liu, Y., and Meng, H. (2014). Analysis of the genetic diversity of garlic (Allium sativum L.) by simple sequence repeat and inter simple sequence repeat analysis and agro-morphological traits. Biochem. System. Ecol. 55, 260-267. https://doi.org/10.1016/j.bse.2014.03.021.

Chinnappareddy L.R.D., Khandagale, K., Chennareddy, A., and Ramappa, V.G. (2013). Molecular markers in the improvement of
Allium crops. Czech J. Genet. Plant Breed. 49(3), 131-139. https:// doi.org/10.17221/111/2013-CJGPB.

Dawood, A.R. (2011). A comparative study of growth, yield and storability of some garlic cultivars and clones under Assiut conditions. M.Sc. thesis (Assiut University, Faculty of Agriculture).

Dawood, A.R., Abd Elaal., S.A., Badawey, A.S., and Attallah, S.Y. (2011). Testing of some garlic (Allium sativum L.) cultivars under Assiut conditions. Assiut J. of Agric. Sci. 42(2), 378-390.

Doyle, J.J., and Doyle, J.L. (1987). A rapid DNA isolation procedure for small quantities of fresh leaf tissue. Phytochem. Bull. 19, 11-15.

Elminadi, N.A. (2002). Studies on garlic production through tissue culture technique. M.Sc. thesis (Cairo University, Faculty of Agriculture).

El-Nagar, M.M., and El-Zohiri, S.S.M. (2015). Physiological and biotechnological studies on some local and foreign garlic genotypes. Indian J. Res. 4(7), 6-11.

Esho, K.B. (2015). Performance of genetic parameters in garlic (Allium sativum L.). Res. J. Agric. Environm. Sci. 2(2), 5-9.

Fang, D.Q., and Roose, M.L. (1997). Identification of closely related citrus cultivars with inter-simple sequence repeat markers. Theor. Appl. Genet. 95(3), 408-417. https://doi.org/10.1007/ s001220050577.

FAO (2012). Economic and Social Department: The Statistical Division.

Figliuolo, G., Candido, V., Logozzo, G., Miccolis, V., and Zeuli, P.S. (2001). Genetic evaluation of cultivated garlic germplasm (Allium sativum L. and A. ampeloprasum L.). Euphytica 121, 325-334. https://doi.org/10.1023/A:1012069532157.

Fritsch, R.M., and Friesen, N. (2002). Evolution, domestication and taxonomy. In Allium Crop Sciences: Recent Advances, H.D. Rabinowitch, and L. Currah, eds. (Wallingford, U.K.: CAB International). https://doi.org/10.1079/9780851995106.0005.

Hammer, Ø., Harper, D.A., and Ryan, P.D. (2001). PAST: Paleontological statistics software package for education and data analysis. Palaeontol. Electron. 4(1), 9.

Heredia-García, E. (2000). Clasificación Taxonómica. In El Ajo en México, E. Heredia-García, and F. Delgadillo-Sánchez, eds. (SAGARINIFAP, Campo Experimental Bajío, Celaya, Gto., Mexico), p. 18-22. ISBN 968-800-486-3.

Islam, M.J., Islam, M.A., Tania, S.A., Saha, S.R., Alam, M.S., and Hasan, M.K. (2004). Performance evaluation of some garlic genotypes in Bangladesh. Asian J. Plant Sci. 3(1), 14-16. https://doi.org/10.3923/ ajps.2004.14.16.

Jabbes, N., Geoffriau, E., Le Clerc, V., Dridi, B., and Hannechi, C. (2011). Inter simple sequence repeat fingerprints for assess genetic diversity of Tunisian garlic populations. J. Agric. Sci. 3(4), 77-85. https://doi.org/10.5539/jas.v3n4p77.

Jo, M.H., Ham, I.K., Moe, K.T., Kwon, S.W., Lu, F.H., Park, Y.J., Kim, W.S., Won, M.K., Kim, T.I., and Lee, E.M. (2012). Classification of genetic variation in garlic (Allium sativum L.) using SSR markers. Australian J. Crop Sci. 6(4), 625-631.

Joshi, S.P., Gupta, V.S., Aggarwal, R.K., Ranjekar, P.K., and Brar, D.S. (2000). Genetic diversity and phylogenetic relationship as revealed by inter simple sequence repeat (ISSR) polymorphism in the genus Oryza. Theor. Appl. Genet. 100(8), 1311-1320. https://doi. org/10.1007/s001220051440.

Kamenetsky, R. (2007). Garlic: Botany and horticulture. Hortic. Rev. 33, 123. https://doi.org/10.1002/9780470168011.ch2. 
Lallemand, J., Messian, C.M., Briand, F., and Etoh, T. (1997). Delimitation of varietal groups in garlic (Allium sativum L.) by morphological, physiological and biochemical characters. Acta Hortic. 433, 123-132. https://doi.org/10.17660/ActaHortic.1997.433.10.

Mohammadi, B., Khodadadi, M., Karami, E., and Shaaf, S. (2014). Variation in agro-morphological characters in Iranian garlic landraces. Intl. J. Veg. Sci. 20(3), 202-215. https://doi.org/10.1080 /19315260.2013.788594.

Mondal, S., Sutar, S.R., and Badigannavar, A.M. (2008). Comparison of RAPD and ISSR marker profiles of cultivated peanut genotypes susceptible or resistant to foliar diseases. J. Food Agric. Environm. 6(2), 181-187.

Mukherjee, A., Sikdar, B., Ghosh, B., Banerjee, A., Ghosh, E., Bhattacharya M., and Roy, S.C. (2013). RAPD and ISSR analysis of some economically important species, varieties, and cultivars of the genus Allium (Alliaceae). Turk. J. Botany 37(4), 605-618. https:// doi.org/10.3906/bot-1208.-18.

Nagaoka, T., and Ogihara, Y. (1997). Applicability of inter-simple sequence repeat polymorphisms in wheat for use as DNA markers in comparison to RFLP and RAPD markers. Theor. Appl. Genet. 94(5), 597-602. https://doi.org/10.1007/s001220050456.

Nagaraju, J., Kathirvel, M., Kumar, R.R., Siddiq, E.A., and Hasnain, S.E. (2002). Genetic analysis of traditional and evolved Basmati and nonBasmati rice varieties by using fluorescence-based ISSR-PCR and SSR markers. Proc. Natl. Sci. Acad. U.S.A. 99(9), 5836-5841. https:// doi.org/10.1073/pnas.042099099.

Panthee, D.R., KC, R.B., Regmi, H.N., Subedi, P.P., Bhattarai, S., and Dhakal, J. (2006). Diversity analysis of garlic (Allium sativum L.) germplasms available in Nepal based on morphological characters. Gen. Res. Crop Evol. 54(1), 205-212. https://doi.org/10.1007/ s10722-004-6690-z.

Paredes, C.M., Becerra, V., and González, A.M.I. (2008). Low genetic diversity among garlic (Allium sativum L.) accessions detected using random amplified polymorphic DNA (RAPD). Chilean J. Agric. Res. 68(1),3-12. https://doi.org/10.4067/S0718-58392008000100001.

Phillips, N.C., Larson, S.R., and Drost, D.T. (2008). Detection of genetic variation in wild populations of three Allium species using amplified fragment length polymorphisms. Hortic. Sci. 43(3), 637-643. https://doi.org/10.21273/HORTSCI.43.3.637.

Pooler, M.R., and Simon, P.W. (1993). Characterization and classification of isozyme and morphological variation in a diverse collection of garlic clones. Euphytica 68(1), 121-130. https://doi. org/10.1007/BF00024161.

Qijiang, C.C., Chengri, C., and Tiejin, J. (2007). Genetic diversity analysis of onion (Allium cepa L.) germplasm by ISSR markers. Chinese Agric. Sci. Bull. 6, 27.

Robledo-Paz, A., and Tovar-Soto, H.M. (2012). Biotechnological tools for garlic propagation and improvement. In Innovations in Biotechnology, E.C. Agbo, ed. (Rijeka, Croatia: In Tech), 474 pp.

Sambrook, J., Fritsch, E.F., and Maniatis, T. (1989). Molecular Cloning: A Laboratory Manual (New Jersey, U.S.A.: Cold Spring Harbor Laboratory).

Sarwat, M. (2012). ISSR: A reliable and cost-effective technique for detection of DNA polymorphism. In Plant DNA Fingerprinting and Barcoding, Methods and Protocols, Ch. 9, N.J. Sucher, J.R. Hennell, and M.C. Carles, eds. (New York, U.S.A.: Humana Press), p. 61-74. https://doi.org/10.1007/978-1-61779-609-8_9.

SAS Institute (2012). SAS 9.3 for Windows.

Senula, A., and Keller, R.J. (2000). Morphological characterization of garlic core collection and establishment of a virus-free in vitro gene bank. Allium Improv. Newsl. 10, 3-5.
Son, J.H., Park, K.C., Lee, S.I., Kim, J.H., and Kim, N.S. (2012). Species relationships among Allium species by ISSR analysis. Hortic. Environm., Biotechn. 53(3), 256-262. https://doi.org/10.1007/ s13580-012-0130-3.

Vavilov, N.I. (1926). Studies on the origin of cultivated plants. Bull. Appl. Bot. 16, 241-248.

Vavilov, N.I. (1951). The origin, variation, immunity and breeding of cultivated plants. Chron. Bot. 13, 361-364.

Volk, G.M., Henk, A.D., and Richards, C.M. (2004). Genetic diversity among U.S. garlic clones as detected using AFLP methods. J. Am. Soc. Hortic. Sci. 129(4), 559-569. https://doi.org/10.21273/ JASHS.129.4.0559.

Wang, H., Li, X., Shen, D., Oiu, Y., and Song, J. (2014). Diversity evaluation of morphological traits and allicin content in garlic (Allium sativum L.) from China. Euphytica 198(2), 243-254. https:// doi.org/10.1007/s10681-014-1097-1.

Wolfe, A.D., Xiang, Q.Y., and Kephart, S.R. (1998). Assessing hybridization in natural populations of Penstemon (Scrophulariaceae) using hypervariable intersimple sequence repeat (ISSR) bands. Molec. Ecol. 77(9), 1107-1125. https://doi.org/10.1046/j.1365294x.1998.00425.x.

Zhao, W.G., Chung, J.W., Lee, G.A., Ma, K.H., Kim, H.H., Kim, K.T., Chung, I.M., Lee, J.K., Kim, N.S., Kim, S.M., and Park, Y.J. (2011). Molecular genetic diversity and population structure of a selected core set in garlic and its relatives using novel SSR markers. Plant Breeding 130, 46-54. https://doi.org/10.1111/j.1439-0523.2010.01805.x.

Received: Sep. 4, 2018

Accepted: Feb. 12, 2021

Addresses of authors:

Gehan A. Elsharkawy ${ }^{1}$, H.H. Hegazi ${ }^{1}$, Ehab Azab ${ }^{2,3}$,

Adil A. Gobouri ${ }^{4, *}$ and S. Ahmed Salat Elnaby ${ }^{5}$

${ }^{1}$ Vegetable Crops Department, Faculty of Agriculture,

Alexandria University, Alexandria, Egypt

2 Department of Biotechnology, College of Science,

Taif University, P.O. Box 11099, Taif 21944, Saudi Arabia

${ }^{3}$ Botany and Microbiology Department, Faculty of Science,

Zagazig University, Zagazig 44519, Sharkia, Egypt

${ }^{4}$ Department of Chemistry, College of Science,

Taif University, P.O. Box 11099, Taif 21944, Saudi Arabia

${ }^{5}$ City of Scientific Research and Technological Applications (SRTA-City), New Borg El-Arab, Egypt

* Corresponding author; E-mail: a.gobouri@tu.edu.sa 